\title{
Aktivitas Antihiperkolesterolemia Ekstrak Batang Dan Akar Kemangi Hutan (Ocimum sanctum) Pada Tikus Putih
}

Magi Melia Tanggu Rame ${ }^{1 *}$, Maria Astriyani Adeodatus ${ }^{2}$, Yohana Krisostoma Anduk Mbulang ${ }^{1}$

${ }^{1}$ Dosen Program Studi Sarjana Farmasi Universitas Citra Bangsa Kupang

${ }^{2}$ Mahasiswa Program Studi Sarjana Farmasi Universitas Citra Bangsa Kupang

*corresponding author

Email: magimelia93@gmail.com

Diterima: 28 Mei 2021

Direvisi : 15 Juni 2021

Publikasi: 20 Juni 2021

doi:10.52216/jfsi.v4i1.70

\section{Abstract}

Hypercholesterolemic is a condition characterized by an increase in fasting Low Density Lipoprotein (LDL) levels without an increase in triglyceride levels and a decrease in HDL (High Density Lipoprotein) levels. Ocimum Sanctum is a plant that can be used as an alternative anti-hypercholesterolemic treatment because it contains alkaloids, flavonoids, tannins, saponins, triterpenoids, and eugenol. The objective of this study is to determine the anti-hypercholesterolemic activity and to determine the most effective dose of extracts of stems and roots of Ocimum sanctum, which can show anti-hypercholesterolemic effects in white rats. A total of 25 male white rats were divided into 5 groups. Group I(simvastatin $0.18 \mathrm{mg} / 200 \mathrm{gr}$ $B W)$, group II (0.5\% Na CMC), groups III, IV and V (extracts of stems and roots of Ocimum sanctum with their respective doses of $50 \mathrm{mg} / \mathrm{kgBW}, 75 \mathrm{mg} / \mathrm{kgBW}$ and $100 \mathrm{mg} / \mathrm{kgBW}$ ) and measured LDL and HDL cholesterol levels using the Direct and Indirect methods. The data obtained were analyzed using ANOVA. The results of statistical analysis showed that there was an anti-hypercholesterolemic effect at the three doses of extracts of stems and roots of Holy Basil (Ocimum Sanctum). The best dose in reducing LDL and increasing HDL compared to simvastatin is $100 \mathrm{mg} / \mathrm{KgBW}$.

Keyword: Anti-hypercholesterolemic, extracts of stems and roots of holy basil, $L D L, H D L$

\section{Intisari}

Hiperkolesterolemia merupakan kondisi yang ditandai dengan peningkatan kadar Low Density Lipoprotein (LDL) Puasa tanpa disertai peningkatan kadar trigliserida dan penurunan kadar High Density Lipoprotein (HDL). Tanaman kemangi hutan merupakan salah satu tanaman yang dapat digunakan sebagai alternatif pengobatan antihiperkolesterolemia karena mengandung senyawa alkaloid, flavonoid, tanin, saponin, triterpenoid, dan eugenol. Penelitian ini bertujuan untuk mengetahui aktivitas antihiperkolesterolemia dan dosis yang paling efektif dari ekstrak batang dan akar kemangi hutan, yang dapat menunjukkan efek antihiperkolesterolemia pada tikus putih. Sebanyak 25 ekor tikus putih jantan dibagi menjadi 5 kelompok. Kelompok I (simvastatin 0,18 mg/200gr BB), kelompok II (Na CMC 0,5\%), kelompok III, IV dan V (ekstrak batang dan akar kemangi hutan dengan dosis $50 \mathrm{mg} / \mathrm{kgBB}, 75 \mathrm{mg} / \mathrm{kgBB}$ dan $100 \mathrm{mg} / \mathrm{kgBB}$ ) dan diukur kadar kolesterol LDL dan HDL menggunakan metode Direct dan Indirect. Data yang diperoleh dianalisis menggunakan ANOVA. Hasil analisis statistik menunjukkan adanya efek antihiperkolesterolemia pada ketiga dosis ekstrak batang dan akar kemangi hutan (Ocimum sanctum). Dosis yang paling baik dalam menurunkan LDL dan meningkatkan HDL dibandingkan dengan simvastatin adalah $100 \mathrm{mg} / \mathrm{KgBB}$.

Kata kunci: Antihiperkolesterolemia, ekstrak batang dan akar kemangi hutan, LDL, HDL. 


\section{Pendahuluan}

Hiperkolesterolemia merupakan kondisi yang ditandai dengan peningkatan kadar Low Density Lipoprotein (LDL) puasa tanpa disertai peningkatan kadar trigliserida. Tingginya kolesterol dapat mendasari atau memicu penyakit lain seperti kekakuan arteri (aterosklerosis) yang merupakan pemicu penyakit jantung koroner (PJK) (Claudi A et al., 2017).

Word Health Organization (WHO) tahun 2017 menyebutkan bahwa penyakit jantung koroner menjadi salah satu masalah kesehatan dalam sistem kardiovaskular yang jumlahnya meningkat cepat dengan angka kematian 6,7 juta kasus. WHO memperkirakan pada tahun 2020, penyakit kardiovaskular akan menyumbang sekitar $25 \%$ dari angka kematian dan mengalami peningkatan khususnya di negara-negara berkembang, di antaranya berada di Asia Tenggara salah satunya negara Indonesia.

Menurut Riset Kesehatan Dasar (RISKESDAS) tahun 2018, menunjukkan bahwa sebesar $1,5 \%$ atau 15 dari 1.000 penduduk Indonesia menderita penyakit jantung koroner.

Berdasarkan jenis kelamin laki-laki dan perempuan yang berumur 15 tahun ke atas, kadar HDL perempuan lebih tinggi dibandingkan lakilaki dengan persentase perempuan sebesar 15,0\% dengan total sebesar $(17,438)$ dan pada laki-laki sebesar $33,7 \%$ dengan total $(17,382)$. Sedangkan berdasarkan jenis kelamin laki-laki dan perempuan yang berumur 15 tahun ke atas, kadar LDL laki-laki lebih tinggi dibandingkan perempuan dengan persentase laki-laki 37,3\% dengan total (17382) dan pada perempuan sebesar $35,4 \%$ dengan total (17438). Prevalensi penyakit jantung berdasarkan diagnosis pada penduduk semua umur di provinsi NTT menduduki peringkat ke 18 dari 34 proyinsi dengan persentase 0,7 sebesar 20,599. Terapi hiperkolesterolemia dapat dilakukan dengan terapi non farmakologi yaitu dengan melakukan pola hidup sehat seperti diet, aktivitas fisik yang cukup, penurunan berat badan, menghentikan kebiasaan merokok dan diet suplemen. Selain itu dapat juga dilakukan dengan terapi farmakologi yang terdiri dari penggunaan obat sintesis (kimia) dan obat tradisional. Salah satu obat antihiperkolesterolemia yang sering digunakan dalam masyarakat adalah golongan statin, dengan mekanisme kerja menghambat kerja dari HMG-CoA reduktase.
Salah satu contoh obat golongan statin yaitu obat simvastatin (Perki, 2013). Penggunaan obat-obatan dengan pemakaian berkepanjangan sering dijumpai berbagai masalah efek samping yang merugikan.

Salah satu tanaman obat tradisional yang telah dikenal dan digunakan oleh masyarakat adalah kemangi hutan (Ocimum sanctum). Tanaman kemangi hutan (Ocimum sanctum) mengandung senyawa alkaloid, flavonoid, tanin, saponin, triterpenoid (Ginting, 2004). Hasil penelitian Rachmawati et al. (2019) menunjukkan daun kemangi hutan (Ocimum sanctum) pada dosis 80 $\mathrm{mg} / \mathrm{kgBB} /$ hari dapat menurunkan kadar kolesterol, trigliserida dan LDL darah tikus putih. Pénelitian dari Suanarunsawat et al. (2011) menunjukkan bahwa senyawa fenolik yang terkandung di dalam ekstrak daun kemangi hutan (Ocimum sanctum) pada dosis 4,45 g/kgBB/hari mempunyai efek menurunkan lipid dan berfungsi sebagai antioksidan untuk melindungi hati dan jantung dari hiperkolesterolemia. Penelitian lain dari Samak et al. (2007) menunjukkan bahwa daun kemangi hutan (Ocimum sanctum) pada dosis 50 $\mathrm{mg} / \mathrm{kgBB} /$ hari dapat menurunkan kadar LDL, meningkatkan kadar HDL dan menurunkan kadar trigliserida.

Berdasarkan penelitian sebelumnya dan kandungan kimia yang dimiliki oleh tanaman kemangi hutan menunjukkan bahwa tanaman ini memiliki potensi sebagai tanaman obat salah satunya dapat mengobati hiperkolesterolemia. Oleh karena itu berdasarkan uraian di atas, maka peneliti tertarik untuk melakukan uji aktivitas antihiperkolesterolemia ekstrak pada bagian tanaman lain dari kemangi hutan yaitu pada batang dan akar kemangi hutan (Ocimum sanctum) terhadap penurunan kadar LDL dan peningkatan kadar HDL pada tikus putih.

\section{Metode Penelitian}

\subsection{Alat dan Bahan}

Alat yang digunakan dalam penelitian ini adalah mesin penggiling, ayakan no.20, botol maserasi, gelas ukur, erlenmeyer, kain flanel, corong gelas, batang pengaduk, timbangan analitik, evaporator, tabung reaksi, batang pengaduk, kandang tikus, timbangan tikus, tabung microhematocrit, centrifuge hematocrit (Wina type 502), tabung darah, fotometer. 
Bahan yang digunakan dalam penelitian ini adalah batang dan akar kemangi hutan yang masih segar yang berwarna coklat, kloroform amoniakal, Mayer, Wagner, akuades, etanol 70\%, larutan HCL pekat, $\mathrm{FeCl}_{3}$, pita $\mathrm{Mg}$, larutan $\mathrm{H} 2 \mathrm{SO} 4$ pekat, asetat anhidrat, metanol, asetat, etanol $70 \%$, simvastatin, $\mathrm{Na} \mathrm{CMC0}, 5 \%$, pakan diet lemak tinggi yaitu kuning telur puyuh dan minyak babi.

Hewan uji dalam penelitian ini adalah tikus jantan galur wistar yang berumur1-1,5 bulan dengan berat badan 150-200 g yang sehat dan tidak cacat, yang diperoleh dari Fakultas Kedokteran Hewan, Universitas Nusa Cendana Kupang.

\subsection{Pembuatan Serbuk Batang dan Akar Kemangi} Hutan

Akar dan batang kemangi hutan diperoleh dari Desa Hoanoa, Kecamatan Noelbaki, Kabupaten Kupang, Nusa Tenggara Timur (NTT). Pengambilan sampel dilakukan dengan cara diacak dan memilih batang dan akar yang segar, tidak terlalu tua serta tidak terlalu muda. Batang dan akar kemangi hutan segar dicuci dengan air mengalir sampai bersih dan ditiriskan untuk menghilangkan kotoran yang masih menempel kemudian dikeringkan. Batang dan akar kemangi hutan yang telah dikeringkan, dihaluskan menggunakan mesin penggiling dan diayak dengan pengayak no.20, kemudian hitung rendemennya.

\subsection{Pembuatan Ekstrak Batang dan Akar Kemangi} Hutan

Sejumlah serbuk halus akar dan batang kemangi hutan dilarutkan dalam pelarut etanol $70 \%$ dengan perbandingan $1: 10 \mathrm{~g} / \mathrm{v}$, kemudian dimasukkan ke dalam bejana maserasi, ditutup, dan dibiarkan selama 5 hari terlindung dari cahaya sambil sesekali dikocok. Setelah 5 hari, campuran tersebut disaring, kemudian filtrat yang diperoleh dipekatkan dengan rotary evaporator pada suhu maksimal $40^{\circ} \mathrm{C}$.

\subsection{Identifikasi Komponen Fitokimia}

\subsubsection{Uji Alkaloid.}

Sebanyak 0,5 gram ekstrak dimasukkan dalam tabung reaksi, lalu ditambahkan dengan $10 \mathrm{ml}$ kloroform amoniakal dan hasilnya di bagi dalam dua tabung. Masing-masing tabung dilakukan pengujian dengan menggunakan pereaksi Mayer dan Wagner. Jika terbentuk endapan maka sampel tersebut menunjukkan adanya alkaloid. (Gafur et al.,2013).

\subsubsection{Uji Saponin}

Sebanyak 0,5 gram ekstrak masukan dalam tabung reaksi tambahkan $2 \mathrm{ml}$ etanol $70 \%$ kemudian diaduk, dan tambahkan $20 \mathrm{ml}$ akuades dan dikocok kuat kemudian diamati selama 15-20 menit. Jika terbentuk busa menunjukkan adanya saponin (Mojab et al., 2003).

\subsubsection{Uji Tanin}

Sebanyak 0,5 gram ekstrak masukan dalam tabung reaksi tambahkan air 1-2 ml, ditambahkan 2 tetes larutan $\mathrm{FeCl} 3$, timbulnya warna biru kehitaman menunjukkan adanya senyawa tanin galat dan jika berwarna hijau kehitaman menunjukkan adanya senyawa tanin katekol (Gafur et al., 2013).

\subsubsection{Uji Flavonoid}

Sebanyak 0,5 gram ekstrak dimasukkan dalam tabung reaksi, ditambahkan $2 \mathrm{ml}$ etanol $70 \%$ kemudian diaduk. Lalu ditambahkan dengan serbuk $\mathrm{Mg}$ dan larutan $\mathrm{HCl}$ pekat. Perubahan warna larutan menjadi merah bata, kuning atau jingga menandakan adanya flavonoid (Mojab et al., 2003).

\subsubsection{Uji Triterpenoid}

Sebanyak 0.5 gram ekstrak dimasukkan dalam tabung reaksi, ditambahkan dengan $0,5 \mathrm{ml}$ kloroform, asetat anhidtrat $0,5 \mathrm{ml}$ kemudian tambahkan $\mathrm{H}_{2} \mathrm{SO}_{4}$ pekat $2 \mathrm{ml}$. Terbentuk cincin kecokelatan atau violet pada perbatasan larutan menunjukkan adanya triterpenoid, sedangkan bila muncul cincin biru kehijauan menunjukkan adanya steroid (Astarina et al., 2013).

\subsubsection{Perlakuan Hewan Uji}

Sebanyak 25 ekor tikus putih yang diberikan pakan standar dan diet lemak tinggi. Kelompok perlakuan dibagi menjadi 5 kelompok yaitu :

Kelompok I : Sebagai kontrol positif, diberikan simvastatin $0,18 \mathrm{mg} / \mathrm{kg}$ BB tikus.

Kelompok II : Sebagai kontrol negatif, diberikan $\mathrm{Na} \mathrm{CMC} 0,5 \%$ 
Kelompok III : Sebagai perlakuan I diberikan ekstrak batang dan akar kemangi hutan $50 \mathrm{mg} / \mathrm{kg}$ BB tikus

Kelompok IV : Perlakuan II diberikan ekstrak batang dan akar kemangi hutan $75 \mathrm{mg} / \mathrm{kg}$ BB tikus

Kelompok V : Perlakuan III diberikan ekstrak batang dan akar kemangi hutan $100 \mathrm{mg} / \mathrm{kg}$ BB tikus.

\subsection{Analisis Data}

Masing-masing data diuji untuk mengetahui ada tidaknya perbedaan bermakna pada parameter antara kelompok perlakuan dengan berbagai perbandingan dosis dengan uji Kolmogorovsmirnof. Data memiliki distribusi normal jika nilai $\mathrm{p}>0,05$ dan memiliki distribusi yang tidak normal jika $\mathrm{p}<0,05$. Jika data terdistribusi normal dilanjutkan dengan uji homogenitas varian. Ketika varian data dinyatakan sama maka dapat dilanjutkan ke tahap uji parametrik. Langkah berikut yang dilakukan yaitu uji One Way ANOVA untuk mendapatkan informasi ada tidaknya perbedaan bermakna antara kelompok perlakuan. Bila $p<0,05$ memiliki arti bahwa terdapat perbedaan bermakna antara kelompok, sedangkan jika $p>0,05$ memiliki arti bahwa tidak terdapat perbedaan bermakna antar kelompok apa pun. Apabila terdapat perbedaan bermakna maka dilakukan uji Tukey post hoc test untuk mengetahui sebenarnya kelompok-kelompok mana yang memiliki perbedaan itu. Semua analisis data menggunakan Software SPSS For Windows versi 22.0 .

\section{Hasil dan Pembahasan}

\subsection{Pembuatan Serbuk Batang dan Akar}

Kemangi Hutan Sebanyak simplisia basah batang 2500 gram dan simplisia basah akar 1500 gram yang dikeringkan didapatkan simplisia kering batang 2000 gram dan simplisia kering akar sebesar 1000 gram. Perhitungan rendemen batang kemangi hutan, menunjukkan bahwa rendemen batang kemangi hutan sebesar $80 \%$ dan akar kemangi hutan sebesar $66,67 \%$.
3.2. Pembuatan Ekstrak Akar dan Batang Kemangi Hutan

Hasil ekstrak kental batang kemangi hutan yang diperoleh sebanyak 17,86 gram dan ekstrak kental akar kemangi hutan sebanyak 18,1 g dengan hasil rendemen dari ekstrak batang kemangi hutan sebanyak 3,53\% dan akar kemangi hutan sebanyak $3,62 \%$. Rendemen ekstrak merupakan hasil dari proses maserasi dan evaporasi simplisia berdasarkan rasio antara berat ekstrak yang dihasilkan dengan simplisia yang digunakan. Kualitas ekstrak yang dihasilkan biasanya berbanding terbalik dengan jumlah rendemen yang dihasilkan. Semakin tinggi nilai rendemen yang dihasilkan maka semakin rendah mutu yang didapatkan (Jimmy Cahyadi et al., 2018). Kuantitas semakin tinggi jumlah pelarut yang digunakan dan lama waktu selama maserasi, maka pengeluaran senyawa target ke dalam pelarut dapat berjalan lebih optimal, sehingga memiliki aktivitas untuk pengobatan (Toar et al., 2020).

3.3. Analisis Komponen Fitokimia Ekstrak Batang dan Akar Kemangi Hutan

Tabel 1. Hasil Analisis Komponen Fitokimia

\begin{tabular}{|c|c|c|}
\hline $\begin{array}{l}\text { Kelompok } \\
\text { senyawa kimia }\end{array}$ & Reagen & Simpulan \\
\hline 196 & $\mathrm{HCl} 2 \mathrm{~N}+$ Mayer & Alkaloid (+) \\
\hline Alkaloid & $\begin{array}{l}\mathrm{HCl} 2 \mathrm{~N}+ \\
\text { Wagner }\end{array}$ & Alkaloid (+) \\
\hline Saponin & $\begin{array}{l}\text { Etanol } \\
70 \%+\text { Akuades }\end{array}$ & $\begin{array}{l}\text { Saponin } \\
(+)\end{array}$ \\
\hline Tanin & $\begin{array}{l}\text { Akuades }+\mathrm{FeCl}_{3}+ \\
\text { Etanol } 70 \%\end{array}$ & $\begin{array}{c}\text { Tanin } \\
(+)\end{array}$ \\
\hline Flavonoid & $\begin{array}{l}\text { Serbuk } \mathrm{Mg}+\mathrm{HCl} \\
\text { pekat }\end{array}$ & $\begin{array}{l}\text { Flavonoid } \\
\qquad(+)\end{array}$ \\
\hline Triterpenoid & $\begin{array}{l}\text { Kloroform + } \\
\text { Asam sulfat pekat } \\
+ \text { Asam asetat }\end{array}$ & $\begin{array}{c}\text { Triterpenoid } \\
\qquad(+)\end{array}$ \\
\hline
\end{tabular}

Hasil analisis kandungan fitokimia menunjukkan bahwa batang dan akar kemangi hutan positif mengandung kelompok senyawa kimia yaitu: alkaloid, saponin, tanin, flavonoid dan triterpenoid. 


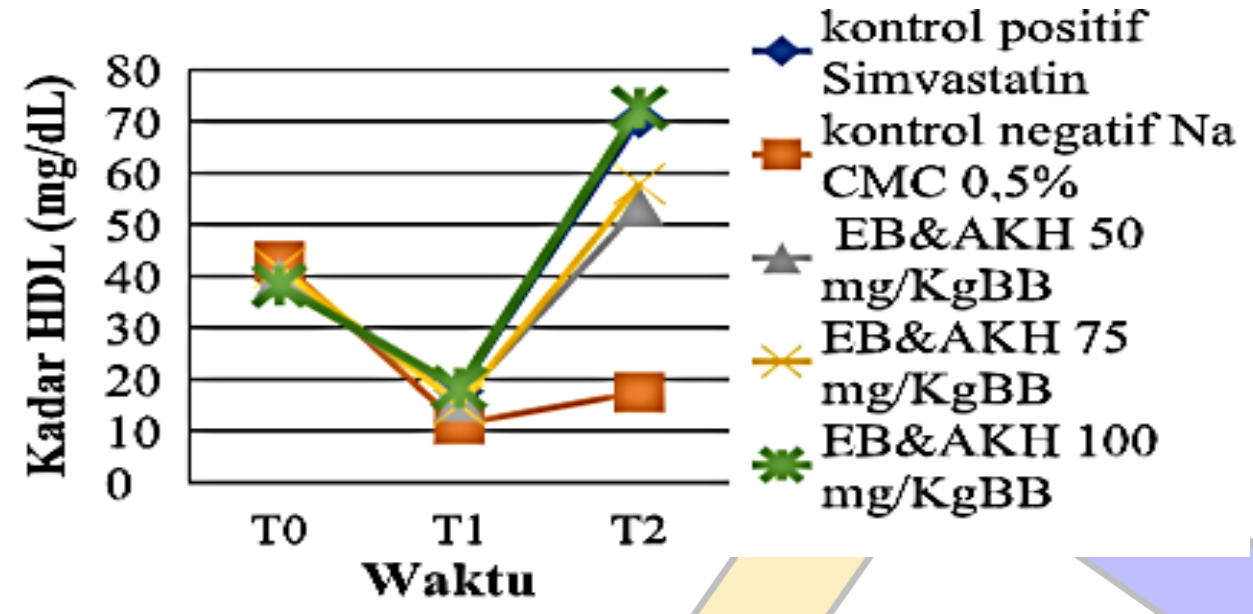

Gambar 1. Peningkatan Kadar HDL

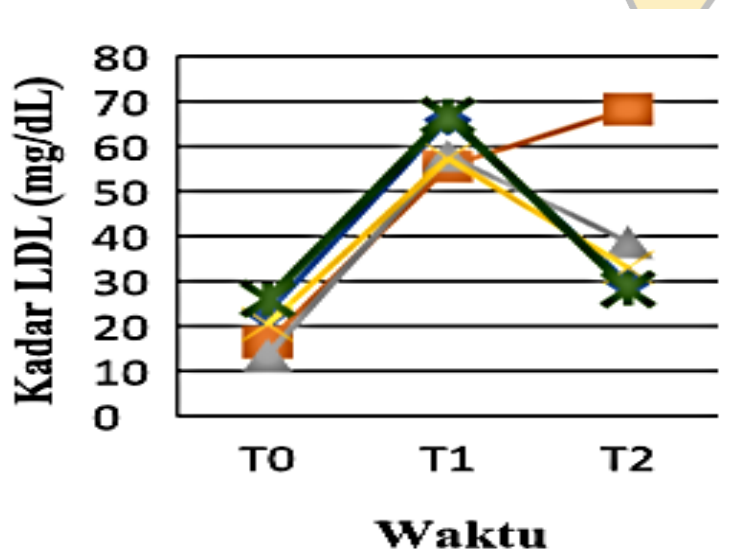

kontrol positif

Simvastatin

kontrol negatif

$\mathrm{Na} C \mathrm{CMC} 0,5 \%$

EB\&AKH 50

$\mathrm{mg} / \mathrm{KgBB}$

EB\&AKII 75

$\mathrm{mg} / \mathrm{KgBB}$

EB\&AKH 100

$\mathrm{mg} / \mathrm{KgBB}$

Gambar 2. Penurunan Kadar LDL

3.4. Pengukuran Kadar Kolesterol LDL dan HDL

Gambar 1 dan 2 di atas menunjukkan terjadinya peningkatan kadar kolesterol HDL dan terjadinya penurunan kadar kolesterol LDL pada setiap kelompok perlakuan. Kadar kolesterol HDL setelah pemberian diet lemak tinggi mengalami penurunan kolesterol HDL dikarenakan peningkatan penyimpanan kolesterol dietary (kolesterol eksogen) di jaringan perifer menyebabkan penurunan konsentrasi HDL yang berperan menginduksi pengeluaran kolesterol dari jaringan perifer (I Made., 2014). Kadar kolesterol LDL mengalami peningkatan disebabkan adanya pemberian diet lemak tinggi. Mengacu pada penelitian Dwinandan et al., 2019 tikus diinduksi diet lemak tinggi selama 14 hari dapat meningkatkan kadar kolesterol.

Peningkatan kolesterol disebabkan adanya pemberian minyak babi mengandung asam lemak jenuh yang tinggi dan kuning telur puyuh mengandung kolesterol sebesar $844 \mathrm{mg} / \mathrm{dL}$ yang menimbulkan jumlah pada asetil-Koa dalam sel hati untuk menghasilkan kolesterol (Ika et al.,
2019). Kelompok ekstrak batang dan akar kemangi hutan dosis I (50 mg/kgBB), dosis II (75 $\mathrm{mg} / \mathrm{kgBB})$, dosis III $(100 \mathrm{mg} / \mathrm{kgBB})$ dapat meningkatkan kadar HDL. Dari ketiga dosis ini dosis III $(100 \mathrm{mg} / \mathrm{kgBB})$ memiliki aktivitas yang lebih baik dari dosis I dan dosis II.

Hal ini disebabkan kandungan senyawa kimia yang terdapat pada tanaman kemangi hutan (Ocimum sanctum) berkhasiat untuk meningkatkan kadar HDL dan menurunkan kadar LDL. Senyawa yang diduga untuk meningkatkan kadar HDL adalah senyawa flavonoid. Flavonoid diketahui dapat menurunkan kadar kolesterol, trigliserida, LDL dan meningkatkan kadar HDL, dengan cara menghambat

3-Hydroxy-3-methylglutary Coenzyme A (HMG-CoA) reduktase yang berfungsi sebagai katalis dalam pembentukan kolesterol (Rahmawati et al., 2019). Senyawa lain yang bekerja untuk meningkatkan kadar kolesterol HDL yaitu triterpenoid, mekanisme triterpenoid melalui aktivasi PPAR- $\alpha$ (Jia et al., 2011). Francis et al. (2003) menyatakan bahwa aktivasi PPAR- $\alpha$ berkontribusi langsung dalam peningkatan kadar 
HDL dalam darah. Semakin tinggi dosis ekstraknya maka semakin besar pula peningkatan kadar HDL, sehingga senyawa kimia yang terdapat dalam ekstrak batang dan akar kemangi hutan dengan dosis III(100 mg/kgBB) mampu menghambat aktivitas enzim HMG-KoA reduktase yang berperan penting dalam penentu kecepatan reaksi reduksi HMGKoA menjadi mevalonat yang akan digunakan untuk pembentukan kolesterol sehingga terjadi peningkatan kadar HDL (Ni Nyoman, 2014).

Senyawa lain yang bekerja untuk menurunkan kolesterol yaitu alkaloid bekerja dengan cara menghambat aktivitas enzim lipase pankreas sehingga meningkatkan sekresi lemak melalui feses (Claudi A. et al., 2017). Tanin dapat mengurangi kolesterol dan LDL dengan meningkatkan metabolisme kolesterol menjadi asam empedu dan meningkatkan ekskresi asam empedu melalui tinja (Rachmawati et al., 2019). Saponin dapat menurunkan kadar kolesterol total dengan meningkatkan garam empedu membentuk suatu senyawa yang tidak dapat diabsorpsi atau membuat garam empedu berikatan dengan polisakarida dalam serat makanan lalu dikeluarkan bersama dengan feses (Cannas A, 2015). Semakin tinggi dosis ekstraknya maka semakin besar pula penurunan kadar LDL. Artinya, senyawa kimia yang terdapat dalam ekstrak batang dan akar kemangi hutan dengan dosis III (100 mg/kgBB) mampu menghambat aktivitas enzim HMG-KoA reduktase yang berperan penting dalam penentu kecepatan reaksi reduksi HMG-KoA menjadi mevalonat yang akan digunakan untuk pembentukan kolesterol sehingga terjadi penurunan kadar LDL (Ni Nyoman,2014).

\subsection{Analisis Statistik}

Data peningkatan kadar kolesterol HDL/dan penurunan LDL dianalisis dengan menggunakan SPSS 22.0. Analisis statistik yang diolah meliputi uji normalitas, homogenitas, ANOVA (one way ANOVA) dan tukey. Uji normalitas dilakukan dengan menggunakan uji Shapiro Wilk karena sampel dalam penelitian ini kurang dari 50 yaitu sebanyak 25 sampel.

Hasil uji normalitas Shapiro-wilk menunjukkan nilai probabilitas dari kelompok kontrol positif simvastatin, kelompok kontrol negatif Na-CMC, kelompok I, Kelompok II dan kelompok III yaitu nilai normalitas p>0,05. Selanjutnya, dilanjutkan dengan uji homogenitas varians menggunakan uji statistik Levene. Uji homogenitas variansi bertujuan untuk melihat variansi dari tiap kelompok. Hasil uji homogenitas untuk kadar kolesterol HDL menunjukkan nilai signifikansi 0,063 (p>0,05) dan kadar kolesterol LDL menunjukkan nilai signifikansi 0,296, sehingga dapat dilanjutkan dengan uji one way ANOVA.

Hasil analisis one way ANOVA dari kadar kolesterol HDL dan LDL menunjukkan nilai signifikansi $\mathrm{p}=0,000 \quad(\mathrm{p}<0,05)$. ANOVA digunakan untuk mengetahui pengaruh utama dan pengaruh interaksi dari variabel independen kategorial terhadap variabel dependen metrik (Ghozali, 2012). Selanjutnya dilanjutkan uji Tukey HSD untuk kadar kolesterol HDL dan LDL menunjukkan bahwa terdapat perbedaan yang signifikan antara kontrol positif (simvastatin), kontrol sediaan uji yang terdiri dari uji I ( $50 \mathrm{mg})$, uji II (75 mg) dan uji HI (100 mg) dengan kontrol negatif (Na CMC) dapat dilihat pada perbedaan subset. Tukey HSD dilakukan untuk menganalisis perbedaan signifikan antara kelompok kontrol positif simvastatin, kelompok kontrol negatif $\mathrm{Na}-$ CMC 0,5\% dan kelompok dosis menunjukkan setiap perlakuan mempunyai perbedaan yang signifikan dari masing-masing perlakuan.

\section{Kesimpulan}

Berdasarkan hasil penelitian dapat disimpulkan bahwa Ekstrak batang dan akar kemangi hutan (Ocimum santum) dapat menurunkan kadar LDL dan meningkatkan kadar HDL pada tikus putih. Dosis III (100mg/kgBB) ekstrak batang dan akar kemangi hutan yang paling optimal dalam menurunkan kadar LDL dan meningkatkan kadar HDL pada tikus putih.

\section{Daftar Pustaka}

Astarina, N. W. G, Astuti, K. W, Warditiani N. K. 2013. Skrining Fitokimia Ekstrak Metanol Rimpang Bangle (Zingiber Purpureum Roxb). Jurusan Farmasi Fakultas Matematika Dan Ilmu Pengetahuan Alam Universitas Udayana.

Cannas A.2015. Departement of Animal SciencePlants Poisonous to Livestock. Cornel 

